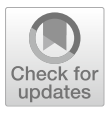

Cite as

Nano-Micro Lett.

(2022) $14: 37$

Received: 15 October 2021

Accepted: 26 November 2021

Published online: 17 December 2021

(C) The Author(s) 2021

\section{Room-Temperature Assembled MXene-Based Aerogels for High Mass-Loading Sodium-Ion Storage}

\author{
Fei Song ${ }^{1}$, Jian $\mathrm{Hu}^{1}$, Guohao $\mathrm{Li}^{1}$, Jie Wang ${ }^{1}$, Shuijiao $\mathrm{Chen}^{2}$, Xiuqiang $\mathrm{Xie}^{1}{ }^{凶}$, \\ Zhenjun $\mathrm{Wu}^{2}$, Nan Zhang ${ }^{1 凶}$
}

\title{
HIGHLIGHTS
}

- Room temperature graphene oxide-assisted assembly of $3 \mathrm{D} \mathrm{Ti}_{3} \mathrm{C}_{2} \mathrm{~T}_{x}$ MXene aerogels have been realized by introducing interfacial mediators (amino-propyltriethoxysilane, $\mathrm{Mn}^{2+}, \mathrm{Fe}^{2+}, \mathrm{Zn}^{2+}$, and $\mathrm{Co}^{2+}$ ).

- The methodology not only suppresses the oxidation degradation of $\mathrm{Ti}_{3} \mathrm{C}_{2} \mathrm{~T}_{x}$, but also generates porous aerogels with a high $\mathrm{Ti}_{3} \mathrm{C}_{2} \mathrm{~T}_{x}$ content $(87 \mathrm{wt} \%)$ and robustness.

- As freestanding electrode of the as-prepared $\mathrm{Ti}_{3} \mathrm{C}_{2} \mathrm{~T}_{x}$-based aerogel with a practical-level mass loading of $12.3 \mathrm{mg} \mathrm{cm}^{-2} \mathrm{still} \mathrm{delivers}$ an areal capacity of $1.26 \mathrm{mAh} \mathrm{cm}^{-2}$ at a current density of $0.1 \mathrm{~A} \mathrm{~g}^{-1}$.

ABSTRACT Low-temperature assembly of MXene nanosheets into three-dimensional (3D) robust aerogels addresses the crucial stability concern of the nano-building blocks during the fabrication process, which is of key importance for transforming the fascinating properties at the nanoscale into the macroscopic scale for practical applications. Herein, suitable cross-linking agents (amino-propyltriethoxysilane, $\mathrm{Mn}^{2+}, \mathrm{Fe}^{2+}, \mathrm{Zn}^{2+}$, and $\mathrm{Co}^{2+}$ ) as interfacial mediators to engineer the interlayer interactions are reported to realize the graphene oxide (GO)-assisted assembly of $\mathrm{Ti}_{3} \mathrm{C}_{2} \mathrm{~T}_{x}$ MXene aerogel at room temperature. This elaborate aerogel construction not only suppresses the oxidation degradation of $\mathrm{Ti}_{3} \mathrm{C}_{2} \mathrm{~T}_{x}$

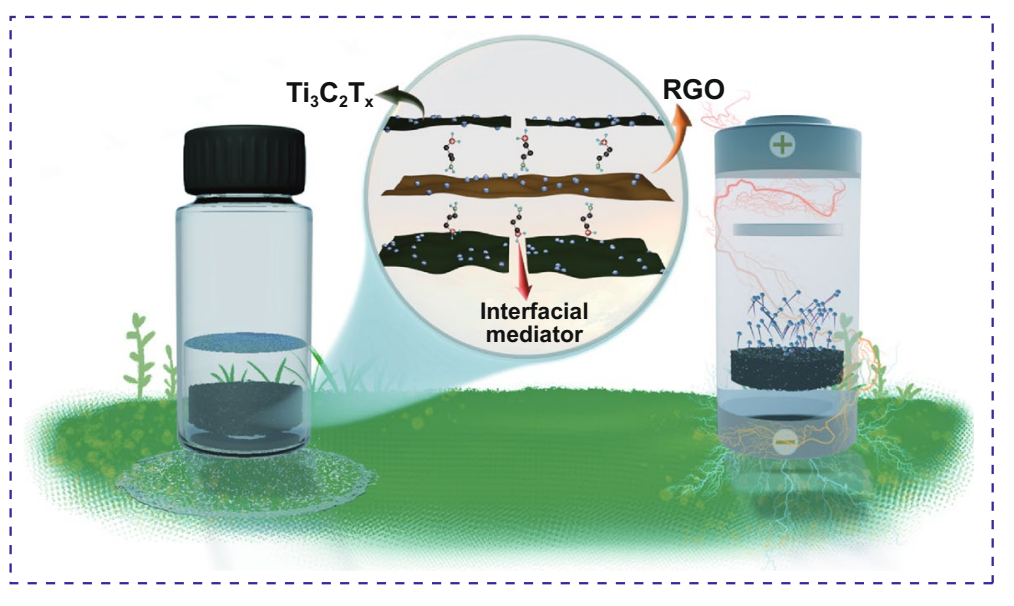
but also generates porous aerogels with a high $\mathrm{Ti}_{3} \mathrm{C}_{2} \mathrm{~T}_{x}$ content $(87 \mathrm{wt} \%)$ and robustness, thereby guaranteeing the functional accessibility of $\mathrm{Ti}_{3} \mathrm{C}_{2} \mathrm{~T}_{x}$ nanosheets and operational reliability as integrated functional materials. In combination with a further sulfur modification, the $\mathrm{Ti}_{3} \mathrm{C}_{2} \mathrm{~T}_{x}$ aerogel electrode shows promising electrochemical performances as the freestanding anode for sodium-ion storage. Even at an ultrahigh loading mass of $12.3 \mathrm{mg} \mathrm{cm}^{-2}$, a pronounced areal capacity of $1.26 \mathrm{mAh} \mathrm{cm}^{-2}$ at a current density of $0.1 \mathrm{~A} \mathrm{~g}^{-1}$ has been achieved, which is of practical significance. This work conceptually suggests a new way to exert the utmost surface functionalities of MXenes in 3D monolithic form and can be an inspiring scaffold to promote the application of MXenes in different areas.

KEYWORDS MXenes; Aerogel; Room-temperature assembly; Interfacial engineering; Sodium-ion storage

Xiuqiang Xie, xiuqiang_xie@ @hu.edu.cn; Zhenjun Wu, wooawt@hnu.edu.cn; Nan Zhang, nanzhang@hnu.edu.cn

College of Materials Science and Engineering, Hunan University, Changsha 410082, People's Republic of China

2 College of Chemistry and Chemical Engineering, Hunan University, Changsha 410082, People's Republic of China 


\section{Introduction}

MXenes, an emerging family of two-dimensional (2D) transition metal carbides and nitrides, have aroused extensive research in many fields [1, 2]. Tens of MXenes have been synthesized and extensively studied, showing promising prospects [3]. As a representative MXene, $\mathrm{Ti}_{3} \mathrm{C}_{2} \mathrm{~T}_{x}$ (where $\mathrm{T}_{x}$ is surface terminations of $-\mathrm{OH},-\mathrm{O}$, and $-\mathrm{F}$ ) is the most widely studied [4-7]. Sodium-ion-based energy storage system has become a candidate for the next-generation energy storage owing to its low cost and abundant resources [8-10]. $\mathrm{Ti}_{3} \mathrm{C}_{2} \mathrm{~T}_{x}$ shows great potential for electrochemical lithiumion, sodium-ion and potassium-ion storage [11-20]. Typically, $\mathrm{Ti}_{3} \mathrm{C}_{2} \mathrm{~T}_{x}$ possesses favorable adsorption [16] energies that fit with the sodium-ion storage [21, 22]. Nevertheless, $2 \mathrm{D} \mathrm{Ti}_{3} \mathrm{C}_{2} \mathrm{~T}_{x}$ nanosheets are prone to restack, which limits the performance and application of the few-layered $\mathrm{Ti}_{3} \mathrm{C}_{2} \mathrm{~T}_{x}$. Especially, it is still a challenge to scale the electrochemical performances of $\mathrm{Ti}_{3} \mathrm{C}_{2} \mathrm{~T}_{x}$ to electrodes with practical-level mass loadings ( $>10 \mathrm{mg} \mathrm{cm}^{-2}$ ) due to the limited ion diffusion in thicker electrodes [23].

Three-dimensional (3D) $\mathrm{Ti}_{3} \mathrm{C}_{2} \mathrm{~T}_{x}$ with favorable surface accessibility represents a suitable integrated functional infrastructure for practical applications, exhibiting promising performances in emerging fields such as electrochemical energy storage and electromagnetic shielding [24-26]. The 3D open structure facilitates faster ion transport and higher surface utilization. Notably, the mutually repulsive hydrophilic groups $\left(-\mathrm{OH},-\mathrm{O}\right.$, etc.) on the surface of $\mathrm{Ti}_{3} \mathrm{C}_{2} \mathrm{~T}_{x}$ make it hard for the cross-linking of adjacent $\mathrm{Ti}_{3} \mathrm{C}_{2} \mathrm{~T}_{x}$ nanosheets directly $[27,28]$. Divalent metal ions have been applied as the initiator for the gelation of $\mathrm{Ti}_{3} \mathrm{C}_{2} \mathrm{~T}_{x}$ colloidal suspension [29]. However, the dissolved free metal ions have limited selectivity for the 3D interconnection of $\mathrm{Ti}_{3} \mathrm{C}_{2} \mathrm{~T}_{x}$ nanosheets, which also lead to the face-to-face restacking of $\mathrm{Ti}_{3} \mathrm{C}_{2} \mathrm{~T}_{x}$, thereby resulting in a less developed interconnected porous structure. Graphene oxide (GO)-assisted assembly of $\mathrm{Ti}_{3} \mathrm{C}_{2} \mathrm{~T}_{x}$ nanosheets has been widely explored, which relies critically on the construction of 3D reduced graphene oxide (RGO) scaffold by balancing the hydrophilicity-hydrophobicity during the reduction of GO. It is worth noting that most of the reported GO-assisted 3D assembly of $\mathrm{Ti}_{3} \mathrm{C}_{2} \mathrm{~T}_{x}$ is carried out at elevated temperatures to afford proper interactions between RGO and $\mathrm{Ti}_{3} \mathrm{C}_{2} \mathrm{~T}_{x}$ while overcoming their electrostatic repulsions (Table $\mathrm{S} 1$ ) [30-33]. This raises the concern of $\mathrm{Ti}_{3} \mathrm{C}_{2} \mathrm{~T}_{x}$ oxidation degradation due to the exposure of thermodynamically metastable marginal transition metal atoms, which sacrifices the appealing properties of $\mathrm{Ti}_{3} \mathrm{C}_{2} \mathrm{~T}_{x}$ [34]. For room temperature GO-assisted 3D assembly of $\mathrm{Ti}_{3} \mathrm{C}_{2} \mathrm{~T}_{x}$, the construction of monolithic structures with a relatively low ratio of $\mathrm{Ti}_{3} \mathrm{C}_{2} \mathrm{~T}_{x}(\leq 70 \mathrm{wt} \%$ ) has been successful, but only aggregated powders can be produced at a higher $\mathrm{Ti}_{3} \mathrm{C}_{2} \mathrm{~T}_{x}$ ratio (Table S1) [35]. The construction of $3 \mathrm{D}$ monolithic aerogels with a high $\mathrm{Ti}_{3} \mathrm{C}_{2} \mathrm{~T}_{x}$ ratio by GOassisted assembly at room temperature is highly desirable to exert the potential of $\mathrm{Ti}_{3} \mathrm{C}_{2} \mathrm{~T}_{x}$ for macroscale applications but remains a challenge. Zhang et al. reviewed the characteristics, treatment methods, interfacial assembly, and applications of MXene colloidal solutions, which provided guidelines for the subsequent study of MXene [36-39].

Noteworthily, the dispersing effect of $\mathrm{Ti}_{3} \mathrm{C}_{2} \mathrm{~T}_{x}$ originating from the electrostatic repulsion between $\mathrm{Ti}_{3} \mathrm{C}_{2} \mathrm{~T}_{x}$ and RGO becomes dominant for the room temperature $\mathrm{GO}$-assisted assembly at a high $\mathrm{Ti}_{3} \mathrm{C}_{2} \mathrm{~T}_{x}$ ratio, which is the key factor destroying the continuous anisotropic intersheet cross-linking of 3D RGO to form integrated structures and thus the formation of $\mathrm{Ti}_{3} \mathrm{C}_{2} \mathrm{~T}_{x} / \mathrm{RGO}$ monoliths. Therefore, our particular interest focuses on the modulation of the interfacial chemistry between $\mathrm{Ti}_{3} \mathrm{C}_{2} \mathrm{~T}_{x}$ and RGO to develop methods for the controllable and efficient assembly of $\mathrm{Ti}_{3} \mathrm{C}_{2} \mathrm{~T}_{x}$ into functional monoliths at room temperature. In this work, suitable cross-linking agents (amino-propyltriethoxysilane, $\mathrm{Mn}^{2+}$, $\mathrm{Fe}^{2+}, \mathrm{Zn}^{2+}$, and $\mathrm{Co}^{2+}$ ) as interfacial mediators have been used to reduce the electrostatic repulsion between electronegative interfaces of $\mathrm{Ti}_{3} \mathrm{C}_{2} \mathrm{~T}_{x}$ and $\mathrm{GO}$ to construct $\mathrm{Ti}_{3} \mathrm{C}_{2} \mathrm{~T}_{x}$ I RGO hydrogels at room temperature. After freeze-drying, the obtained $\mathrm{Ti}_{3} \mathrm{C}_{2} \mathrm{~T}_{x} / \mathrm{RGO}$ composite aerogels possess excellent structural robustness even at a high $\mathrm{Ti}_{3} \mathrm{C}_{2} \mathrm{~T}_{x}$ ratio of $87 \mathrm{wt} \%$, which renders the $\mathrm{Ti}_{3} \mathrm{C}_{2} \mathrm{~T}_{x} / \mathrm{RGO}$ composite aerogel a potential candidate for fabricating self-supporting electrodes for electrochemical sodium storage. When $\mathrm{Ti}_{3} \mathrm{C}_{2} \mathrm{~T}_{x}$ ' RGO composite aerogels are applied to electrochemical energy storage, we refer to the sulfur template and surface modification methods reported in the literature to improve the electrochemical performance of the material [40-42]. On the basis of the developed strategy, sulfur modification has been further performed by using elemental sulfur/ $/ \mathrm{Ti}_{3} \mathrm{C}_{2} \mathrm{~T}_{x}$ composites $\left(\mathrm{S} / \mathrm{Ti}_{3} \mathrm{C}_{2} \mathrm{~T}_{x}\right)$ as the starting material followed by thermal treatment to prepare the sulfur-doped $\mathrm{Ti}_{3} \mathrm{C}_{2} \mathrm{~T}_{x} / \mathrm{RGO}$ aerogels for electrochemical sodium storage. Encouragingly, benefiting from the enhanced charge transfer kinetics due 
to the favorable porous structure and sulfur modification, a pronounced areal capacity of $1.26 \mathrm{mAh} \mathrm{cm}^{-2}$ at a current density of $0.1 \mathrm{~A} \mathrm{~g}^{-1}$ has been achieved at a high loading mass of $12.3 \mathrm{mg} \mathrm{cm}^{-2}$, demonstrating great promise for practical applications.

\section{Experimental}

\subsection{Preparation of $\mathrm{Ti}_{3} \mathrm{C}_{2} \mathrm{~T}_{x}$ and GO}

$\mathrm{Ti}_{3} \mathrm{C}_{2} \mathrm{~T}_{x}$ colloid suspension was synthesized by selectively etching $\mathrm{Al}$ elements from the $\mathrm{Ti}_{3} \mathrm{AlC}_{2} \mathrm{MAX}$ phase with $\mathrm{LiF} /$ $\mathrm{HCl}[43,44]$. Briefly, $3.2 \mathrm{~g}$ of $\mathrm{LiF}$ was dissolved in $40 \mathrm{~mL}$ $(9 \mathrm{M}) \mathrm{HCl}$ solution and stirred uniformly in a Teflon reactor. Then, $2 \mathrm{~g}$ of $\mathrm{Ti}_{3} \mathrm{AlC}_{2}$ powder was steadily added to the above solution, followed by magnetic stirring at $35^{\circ} \mathrm{C}$ for $24 \mathrm{~h}$ in a fume hood. After that, the obtained slurry was washed to neutral with deionized water by repeated centrifugation and at $7000 \mathrm{rpm}$. Next, deionized water was added to the $\mathrm{Ti}_{3} \mathrm{C}_{2} \mathrm{~T}_{x}$ slurry and the ultrasonic treatment was applied under the protection of $\mathrm{N}_{2}$. Finally, the $\mathrm{Ti}_{3} \mathrm{C}_{2} \mathrm{~T}_{x}$ colloid suspension was obtained after centrifugation at $3500 \mathrm{rpm}$ for $1 \mathrm{~h}$. GO was synthesized from natural graphite powder according to the modified Hummers method [45].

\subsection{Assembly of MGA}

A $60 \mathrm{mg} \mathrm{Ti}{ }_{3} \mathrm{C}_{2} \mathrm{~T}_{x}$ powder obtained by freeze-drying above $\mathrm{Ti}_{3} \mathrm{C}_{2} \mathrm{~T}_{x}$ colloid suspension and $1 \mathrm{~mL}$ of GO solution $\left(10 \mathrm{mg} \mathrm{mL}^{-1}\right.$ ) were mixed and ground in a mortar for minutes until a uniform black slurry formed. Subsequently, 10 $\mu \mathrm{L}$ of APTES was added to the mixed slurry as an interfacial mediator, and further stirring was performed for uniform mixing. After that, $4 \mathrm{~mL}$ of $\mathrm{VC}$ solution $\left(0.25 \mathrm{~g} \mathrm{~mL}^{-1}\right)$ was added to the mixed slurry and stirred for another $20 \mathrm{~min}$. Thereafter, the mixture was immediately transferred and sealed into a $20 \mathrm{~mL}$ glass vial for slow reduction at $25{ }^{\circ} \mathrm{C}$ for $72 \mathrm{~h}$. A black $\mathrm{Ti}_{3} \mathrm{C}_{2} \mathrm{~T}_{x} / \mathrm{RGO}$ hydrogel gradually formed, and the solution became yellow. After the reaction, the yellow solution was poured out mildly, and the hydrogel was washed with deionized water to remove excess reactants and impurities. The $\mathrm{Ti}_{3} \mathrm{C}_{2} \mathrm{~T}_{x} / \mathrm{RGO}$ aerogels were obtained by freeze-drying the above $\mathrm{Ti}_{3} \mathrm{C}_{2} \mathrm{~T}_{x} /$ RGO hydrogel and sintering in a tube furnace at $400{ }^{\circ} \mathrm{C}$ under $\mathrm{N}_{2}$ for $4 \mathrm{~h}$. Both deionized water washing and heat-treatment help to remove $\mathrm{VC}$ residues. In a similar way, APTES was replaced with $10 \mathrm{mg}$ of metal ions salts $\left(\mathrm{MnCl}_{2}, \mathrm{FeCl}_{2}, \mathrm{ZnCl}_{2}\right.$, and $\left.\mathrm{Co}\left(\mathrm{CH}_{3} \mathrm{COO}\right)_{2}\right)$ dissolved in $0.5 \mathrm{~mL}$ of deionized water to obtain $\mathrm{Ti}_{3} \mathrm{C}_{2} \mathrm{~T}_{x} / \mathrm{RGO}$ hydrogels cross-linked by different metal ions. To alleviate the oxidation induced by these metal ions, $\mathrm{N}_{2}$ bubbling was additionally applied.

\subsection{Assembly of SMGA}

$\mathrm{Ti}_{3} \mathrm{C}_{2} \mathrm{~T}_{x} @ \mathrm{~S}$ composites were prepared using a modification of the method reported by Tang et al. [46]. Sodium polysulfides (NaPS) was selected as a suitable sulfur source. Specifically, $0.4 \mathrm{~g}$ of sodium sulfide and $60 \mathrm{mg}$ of elemental sulfur were dissolved in $10 \mathrm{~mL}$ of deionized water and treated in an oven at $80^{\circ} \mathrm{C}$ overnight to obtain a yellow NaPS solution. Then, $10 \mathrm{~mL}$ of $\mathrm{Ti}_{3} \mathrm{C}_{2} \mathrm{~T}_{x}$ suspension $\left(6 \mathrm{mg} \mathrm{mL}^{-1}\right)$ and $10 \mathrm{~mL}$ of NaPS solution were mixed and stirred well for $10 \mathrm{~min}$. Afterward, formic acid was added dropwise to the above solution under stirring until the $\mathrm{pH}$ was close to neutral. The mixed solution was then centrifuged and washed twice with deionized water to remove impurities and the products were freeze-dried for further assembly. In short, the pure $\mathrm{Ti}_{3} \mathrm{C}_{2} \mathrm{~T}_{x}$ mentioned in the assembly of $\mathrm{Ti}_{3} \mathrm{C}_{2} \mathrm{~T}_{x} / \mathrm{RGO}$ hydrogel was replaced with $\mathrm{Ti}_{3} \mathrm{C}_{2} \mathrm{~T}_{x} @ \mathrm{~S}$ to prepare MGA@S. And SMGA was obtained through heat-treatment in a tube furnace at $400{ }^{\circ} \mathrm{C}$ under $\mathrm{N}_{2}$ for $4 \mathrm{~h}$.

\subsection{Characterizations}

\subsubsection{Structure Characterizations}

The structures, morphologies, and elemental mappings of MGA, SMGA were investigated by a transmission electron microscope (TEM, Titan G260-300) at an accelerating voltage of $200 \mathrm{kV}$, a scanning electron microscope (SEM, Hitachi S4800), X-ray photoelectron spectrometer (XPS, AXIS SUPRA), X-ray diffraction instrument (XRD, Rigaku MiniFlex) using Ni-filtered $\mathrm{Cu} \mathrm{K} \alpha$ radiation at a scan rate of $10^{\circ} \mathrm{min}^{-1}$, a Raman spectrometer (invia-reflex with $532 \mathrm{~nm}$ wavelength laser). The Zeta potentials of $\mathrm{Ti}_{3} \mathrm{C}_{2} \mathrm{~T}_{x}$, $\mathrm{GO}, \mathrm{Ti}_{3} \mathrm{C}_{2} \mathrm{~T}_{x} / \mathrm{GO}, \mathrm{Ti}_{3} \mathrm{C}_{2} \mathrm{~T}_{x} / \mathrm{GO} \&$ APTES solution were tested using a zeta potential analyzer (Zetasizer Nano ZSP). The specific surface areas were tested using a Micromeritics ASAP2460 based on the Brunauer-Emmett-Teller (BET) method. 


\subsubsection{Electrochemical Measurements}

MGA and SMGA were fabricated as freestanding electrodes by slicing and pressing using a micro tableting machine (KJGROUP, YLJ-20). For sodium-ion cells, the electrochemical measurements were performed in CR2032 type coin halfcells, which were assembled in the argon-filled glove box with oxygen and moisture below $0.01 \mathrm{ppm}$ (Mikrouna). Na foil was used as the counter electrode, glass fiber (Whatman GF/A) was used as the separator, and $1.0 \mathrm{M} \mathrm{NaClO}_{4}$ dissolved in a mixture of EC and DEC $(1: 1 \mathrm{v} / \mathrm{v})$ with $5 \mathrm{wt} \%$ fluorinated ethylene carbonate (FEC) as the electrolyte. The CV and EIS tests were carried out on the CHI660E electrochemical workstation. Galvanostatic charge/discharge measurements were performed in a potential range of 0.01 and $3.0 \mathrm{~V}\left(\mathrm{vs} . \mathrm{Na}^{+} / \mathrm{Na}\right)$ at different current densities using a battery test system (Neware). For the sodium-ion hybrid capacitor, SMGA (about $0.6 \mathrm{mg}$ ) and activated carbon (YP50F) $(2.4 \mathrm{mg})$ were selected as anode and cathode electrodes, respectively. And both electrodes were pre-activated in halfcells by pairing with pure $\mathrm{Na}$ foil. To increase the stability of the electrodes and avoid the impact of side reactions, the anode was cycled from 0.01 to $3 \mathrm{~V}$ for 10 times and stopped at $0.8 \mathrm{~V}$, while the cathode was cycled 10 times from 2.0 to $4.0 \mathrm{~V}$ and stopped at $2.0 \mathrm{~V}$. Specifically, the multiple cycles contribute to the formation of a stable SEI of the anode and alleviate the effects of irreversible reactions of the anode and cathode. A suitable cut-off voltage will ensure sufficient sodium ions pre-embedded the electrode. The potential window of the hybrid capacitor was set to be $0.01-4.0 \mathrm{~V}$.

\section{Results and Discussion}

The synthesis process of $\mathrm{Ti}_{3} \mathrm{C}_{2} \mathrm{~T}_{x} / \mathrm{RGO}$ is schematically depicted in Fig. 1a. Typically, delaminated $\mathrm{Ti}_{3} \mathrm{C}_{2} \mathrm{~T}_{x}$ suspension has been evenly mixed with the GO colloidal solution $\left(10 \mathrm{mg} \mathrm{ml}^{-1}\right)$ in a mortar. Interfacial mediators have been added to the mixture followed by continuous stirring. Then, ascorbic acid (VC) solution has been added to the above mixture for the reduction gelation of GO. Immediately afterward, the above slurry has been transferred to a glass vial. After $72 \mathrm{~h}$ at $25^{\circ} \mathrm{C}$, a uniform $\mathrm{Ti}_{3} \mathrm{C}_{2} \mathrm{~T}_{x} / \mathrm{RGO}$ hydrogel has formed automatically and $\mathrm{Ti}_{3} \mathrm{C}_{2} \mathrm{~T}_{x} / \mathrm{RGO}$ monolith has been obtained after washing and freeze-drying at $-40{ }^{\circ} \mathrm{C}$ [47]. For amino-propyltriethoxysilane (APTES) as the interfacial mediator, it undergoes hydrolysis in the presence of water and the exposed silyl and cationic amino groups will interact with hydroxyl groups on the surfaces of $\mathrm{Ti}_{3} \mathrm{C}_{2} \mathrm{~T}_{x}$ and GO by hydrogen bonding to form a cross-linking structure (Fig. 1b). The cross-linking effect of APTES on bridging $\mathrm{Ti}_{3} \mathrm{C}_{2} \mathrm{~T}_{x}$ and $\mathrm{GO}$ is verified by Zeta potential analysis (Fig. 1c). Both $\mathrm{Ti}_{3} \mathrm{C}_{2} \mathrm{~T}_{x}$ and GO are negatively charged, forming stable colloids in water (Fig. S1a, b). As a result, the $\mathrm{Ti}_{3} \mathrm{C}_{2} \mathrm{~T}_{x} / \mathrm{GO}$ mixed colloid is stable and no aggregation is found due to the electrostatic repulsion between $\mathrm{Ti}_{3} \mathrm{C}_{2} \mathrm{~T}_{x}$ and GO (Fig. S1c). After adding APTES, the Zeta potential of $\mathrm{Ti}_{3} \mathrm{C}_{2} \mathrm{~T}_{x} / \mathrm{GO}$ shifts positively from -40 to $-11 \mathrm{mV}$. This suggests that the introduction of APTES reduces the electrostatic repulsion between $\mathrm{Ti}_{3} \mathrm{C}_{2} \mathrm{~T}_{x}$ and GO effectively, which is of key importance to overcome the dispersing effect of $\mathrm{Ti}_{3} \mathrm{C}_{2} \mathrm{~T}_{x}$ at a high $\mathrm{Ti}_{3} \mathrm{C}_{2} \mathrm{~T}_{x} / \mathrm{GO}$ mass ratio for the construction of $\mathrm{Ti}_{3} \mathrm{C}_{2} \mathrm{~T}_{x} /$ RGO composite aerogels. As a demonstration, when excess APTES has been added to the $\mathrm{Ti}_{3} \mathrm{C}_{2} \mathrm{~T}_{x} / \mathrm{GO}$ mixed colloid directly, the flocculent cross-linked aggregation has quickly formed in the solution (Fig. S1d), which intuitively shows the cross-linking effect of APTES.

For the control experiment without any interfacial mediators, no monolithic assembly has been obtained when the $\mathrm{Ti}_{3} \mathrm{C}_{2} \mathrm{~T}_{x} / \mathrm{GO}$ mass ratio is 6:1 with no APTES (NA) (Fig. 2a). In contrast, the introduction of APTES leads to the successful formation of well-defined hydrogels with $\mathrm{Ti}_{3} \mathrm{C}_{2} \mathrm{~T}_{x} / \mathrm{GO}$ ratios ranging from 2:1 to as high as 6:1 (Fig. 2b-d). As such, it unravels the essential role of APTES in mediating the interfacial interactions between $\mathrm{Ti}_{3} \mathrm{C}_{2} \mathrm{~T}_{x}$ and $\mathrm{GO}$ in the construction of monoliths with a high $\mathrm{Ti}_{3} \mathrm{C}_{2} \mathrm{~T}_{x}$ content by the GO-assisted assembly at room temperature. Notably, excessive APTES (EA) has caused fast aggregation of $\mathrm{Ti}_{3} \mathrm{C}_{2} \mathrm{~T}_{x} / \mathrm{GO}$ mixed colloid, resulting in the generation of sediment instead of hydrogel, as shown in Fig. 2e. Appropriate amount of positively charged APTES will crosslink the negatively charged $\mathrm{Ti}_{3} \mathrm{C}_{2} \mathrm{~T}_{x}$ nanosheets and $\mathrm{GO}$ nanosheets. In this case, the mixed solution can remain relatively stable and form a uniform 3D structure. However, excessive APTES hydrolysates to cross-link with $\mathrm{Ti}_{3} \mathrm{C}_{2} \mathrm{~T}_{x}$ nanosheets, which will destroy the electrostatic equilibrium of colloid solution and limit the formation of the uniform porous gel structure. The aerogel prepared from a nominal $\mathrm{Ti}_{3} \mathrm{C}_{2} \mathrm{~T}_{x} / \mathrm{GO}$ mass ratio of 6:1 is denoted as MGA (MXene/RGO aerogel), which can support $100 \mathrm{~g}$ weight without significant deformation (Fig. 2f). This suggests that a small ratio of $\mathrm{GO}$ can form a 3D continuous network with the assistance 


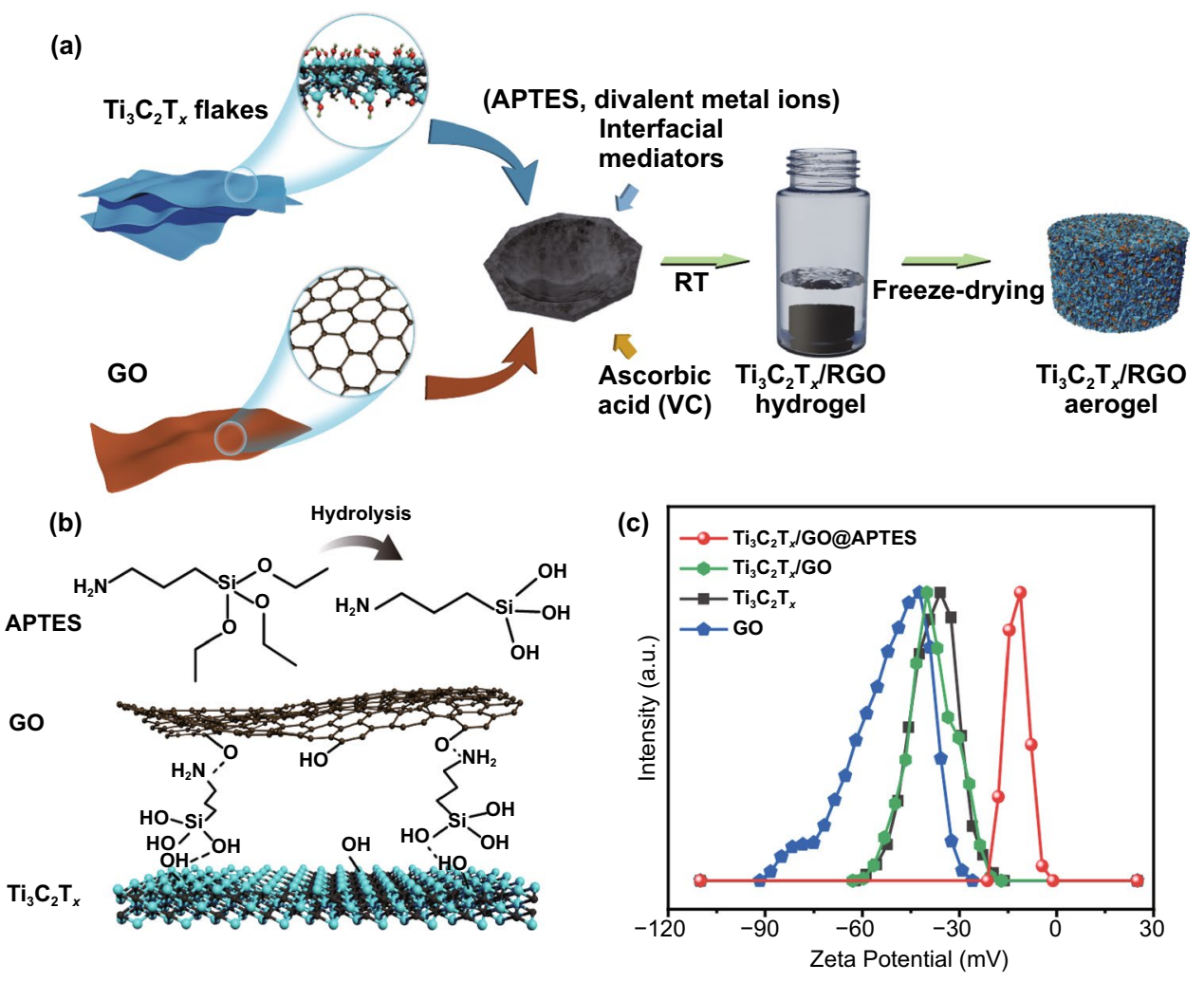

Fig. 1 a Schematic illustration of the synthetic process of $\mathrm{Ti}_{3} \mathrm{C}_{2} \mathrm{~T}_{x} / \mathrm{RGO}$ aerogels. $\mathbf{b}$ Diagram of the cross-linking of $\mathrm{Ti}_{3} \mathrm{C}_{2} \mathrm{~T}_{x}$ and $\mathrm{RGO}$ nanosheets by the hydrolyzed APTES. $\mathbf{c}$ Zeta potentials of $\mathrm{Ti}_{3} \mathrm{C}_{2} \mathrm{~T}_{x}, \mathrm{GO}, \mathrm{Ti}_{3} \mathrm{C}_{2} \mathrm{~T}_{x} / \mathrm{GO}$, and $\mathrm{Ti}_{3} \mathrm{C}_{2} \mathrm{~T}_{x} / \mathrm{GO}$ with the addition of APTES

of the interfacial mediator of APTES for the encapsulation of $\mathrm{Ti}_{3} \mathrm{C}_{2} \mathrm{~T}_{x}$ nanosheets to form a robust monolith with promising mechanical strength. Based on the weights of MGA (62 $\mathrm{mg})$ and bare RGO aerogel $(8 \mathrm{mg}$ ) prepared in a similar method without $\mathrm{Ti}_{3} \mathrm{C}_{2} \mathrm{~T}_{x}$, it is estimated that the ratio in the resulting MGA is around $87 \mathrm{wt} \%$. Further experiment shows that it is feasible to scale up the method presented here to construct a larger MGA with a diameter of $7.8 \mathrm{~cm}$ (Fig. $\mathrm{S} 2$ ). Inspired by the role of APTES in screening the electrostatic repulsion between $\mathrm{Ti}_{3} \mathrm{C}_{2} \mathrm{~T}_{x}$ and $\mathrm{GO}$, different cationic metal ions have been selected as similar interfacial mediators for the construction of $\mathrm{Ti}_{3} \mathrm{C}_{2} \mathrm{~T}_{x}$-based monoliths under the same condition. As shown in Fig. $2 \mathrm{~g}-\mathrm{j}$, various metal ions $\left(\mathrm{Mn}^{2+}, \mathrm{Fe}^{2+}, \mathrm{Zn}^{2+}\right.$, and $\left.\mathrm{Co}^{2+}\right)$ have also realized the successful assembly of monoliths at a $\mathrm{Ti}_{3} \mathrm{C}_{2} \mathrm{~T}_{x} / \mathrm{GO}$ mass ratio of $6: 1$ with good structural robustness. The structural robustness is highly desirable for practical applications where integrated $\mathrm{Ti}_{3} \mathrm{C}_{2} \mathrm{~T}_{x}$-based functional materials are required. Noteworthily, Yang and coworkers have shown that divalent metal ions lead to the $3 \mathrm{D}$ gelation of $\mathrm{Ti}_{3} \mathrm{C}_{2} \mathrm{~T}_{x}$ colloid [29]. Divalent metal ions are advantageous in terms of cross-linking while avoiding the oxidation of $\mathrm{Ti}_{3} \mathrm{C}_{2} \mathrm{~T}_{x}$ than monovalent and trivalent metal ions. Unfortunately, it is found that the aerogels obtained by cross-linking $\mathrm{Ti}_{3} \mathrm{C}_{2} \mathrm{~T}_{x}$ directly with metal ions in the absence of GO show poor mechanical strength compared to the counterparts with GO, which have been readily broken down into powders under pressing (Fig. S3). More encouragingly, the room-temperature GO-assisted assembly of $\mathrm{Ti}_{3} \mathrm{C}_{2} \mathrm{~T}_{x}$ MXene modulated by interfacial mediators is feasible for further modifications by incorporating other functional nanomaterials with $\mathrm{Ti}_{3} \mathrm{C}_{2} \mathrm{~T}_{x}$ as the starting material. As a paradigm, we have used sulfur nanoparticles loaded $\mathrm{Ti}_{3} \mathrm{C}_{2} \mathrm{~T}_{x}$ nanosheets $\left(\mathrm{S} / \mathrm{Ti}_{3} \mathrm{C}_{2} \mathrm{~T}_{x}\right)$ in a similar way to produce S@MGA while maintaining a same $\mathrm{Ti}_{3} \mathrm{C}_{2} \mathrm{~T}_{x} / \mathrm{GO}$ ratio of 6:1 to that of MGA, and sulfur modified MGA (SMGA) was prepared after eliminating sulfur nanoparticles by heattreatment at $400{ }^{\circ} \mathrm{C}$ (Fig. S4). The obtained SMGA exhibits excellent mechanical integrity and remains in hydrophobic state in continuous ultrasonic treatment for $150 \mathrm{~min}$ (Fig. S5), demonstrating the good structural stability.

The microstructures have been characterized by scanning electron microscopy (SEM). As shown in Fig. S6, 
(a)

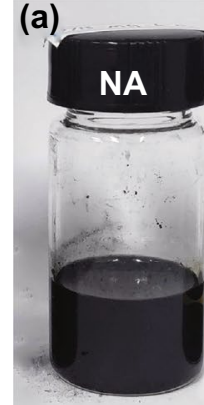

(f)

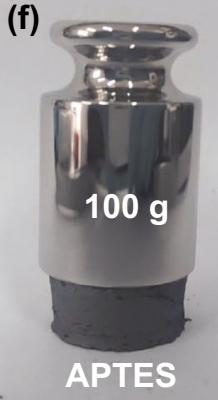

(b)

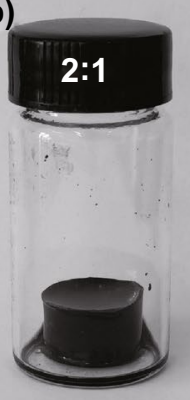

(g)

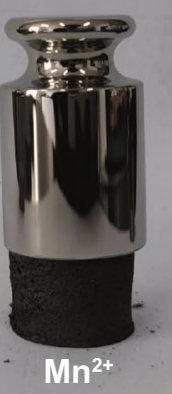

(c)

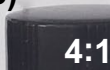

(d)

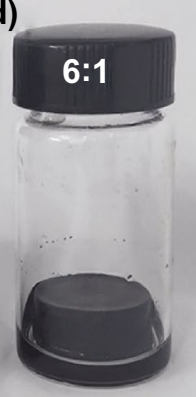

(h)

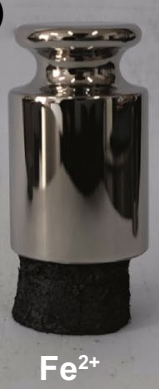

(i)

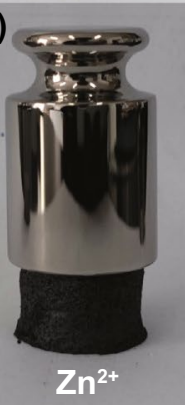

(e)

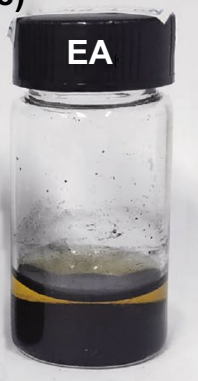

(j)

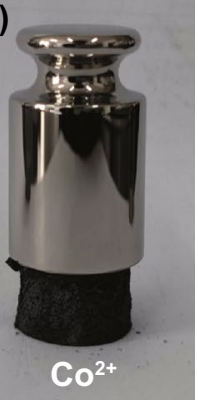

Fig. 2 Room temperature assembly of $\mathrm{Ti}_{3} \mathrm{C}_{2} \mathrm{~T}_{x}$. a $\mathrm{Ti}_{3} \mathrm{C}_{2} \mathrm{~T}_{x} / \mathrm{RGO}$ mixture without adding interfacial mediators. b-d Ti ${ }_{3} \mathrm{C}_{2} \mathrm{~T}_{x} / \mathrm{RGO}$ hydrogels obtained from different $\mathrm{Ti}_{3} \mathrm{C}_{2} \mathrm{~T}_{x} / \mathrm{GO}$ ratios from 2:1 to 6:1. e $\mathrm{Ti}_{3} \mathrm{C}_{2} \mathrm{~T}_{x} / \mathrm{RGO}$ with excessive APTES addition. $\mathbf{f}-\mathbf{j}$ Photos of Ti ${ }_{3} \mathrm{C}_{2} \mathrm{~T}_{x} / \mathrm{RGO}$ aerogels prepared from a $\mathrm{Ti}_{3} \mathrm{C}_{2} \mathrm{~T}_{x} / \mathrm{GO}$ ratio of $6: 1$ by using different interfacial mediators bearing $100 \mathrm{~g}$ weight

MGA has a typical 3D structure formed by interconnected nanosheets, which prevents aggregation of the 2D nanobuilding blocks, thereby promoting the surface accessibility for practical applications. Similarly, SMGA has a 3D interconnected porous structure identical to MGA, showing that the developed protocol for the 3D assembly of $\mathrm{Ti}_{3} \mathrm{C}_{2} \mathrm{~T}_{x}$ is viable for the further sulfur modification process (Fig. 3a). The morphology and interfacial interactions between $\mathrm{Ti}_{3} \mathrm{C}_{2} \mathrm{~T}_{x}$ and RGO in SMGA have been investigated by TEM. As shown in Fig. 3b, a visible porous structure is observed, which is consistent with the SEM observations. Specially, no particulate $\mathrm{TiO}_{2}$ is present, indicating that the oxidation of $\mathrm{Ti}_{3} \mathrm{C}_{2} \mathrm{~T}_{x}$ is effectively suppressed. In the high-resolution TEM (HRTEM) image (Fig. 3c), $\mathrm{Ti}_{3} \mathrm{C}_{2} \mathrm{~T}_{x}$ nanosheets could be easily distinguished from RGO nanosheets through the layer thickness because RGO consists of a single $\mathrm{C}$ layer while three Ti layers are interspersed alternately with two $\mathrm{C}$ layers for $\mathrm{Ti}_{3} \mathrm{C}_{2} \mathrm{~T}_{x}$. And the intimate interfacial contact between $\mathrm{Ti}_{3} \mathrm{C}_{2} \mathrm{~T}_{x}$ and RGO nanosheets are observed, which confirms the effective cross-linking between $\mathrm{Ti}_{3} \mathrm{C}_{2} \mathrm{~T}_{x}$ and GO. Additionally, the elemental mapping analysis shows the homogeneous distribution of Ti, C, S, and Si (Fig. 3d, e). Among them, the presence of Si confirms the essential role of APTES in bridging $\mathrm{Ti}_{3} \mathrm{C}_{2} \mathrm{~T}_{x}$ and RGO. Since no obvious sulfur nanoparticles is observed in the TEM image in Fig. 3b, it is believed that $\mathrm{S}$ exists primarily as the lattice dopant in the resulting SMGA, which will be further elaborated in the following discussions. And there is no $\mathrm{TiO}_{2}$ nanoparticles on the smooth surface of the obtained sample in TEM image, further indicating that the $\mathrm{Ti}_{3} \mathrm{C}_{2} \mathrm{~T}_{x}$ has not been oxidized significantly.

Figure 4a shows the XRD patterns of the samples. The prominent peaks at around $6^{\circ}$ corresponding to the (002) crystal plane of $\mathrm{Ti}_{3} \mathrm{C}_{2} \mathrm{~T}_{x}$ are observed in all samples. Compared with bare $\mathrm{Ti}_{3} \mathrm{C}_{2} \mathrm{~T}_{x}$ film prepared by vacuum filtration of $\mathrm{Ti}_{3} \mathrm{C}_{2} \mathrm{~T}_{x}$ colloid, the (002) diffraction peak for MGA shifts from $6.5^{\circ}$ to $6.3^{\circ}$, which indicates the effective suppression of the face-to-face restacking due to the 3D assembly. In addition, a diffraction appears to peak at $25^{\circ}$ for MGA, corresponding to the (002) crystal plane of RGO. For S@MGA, the typical diffraction peaks of $\mathrm{S}$ are discernable and the (002) diffraction peak of $\mathrm{Ti}_{3} \mathrm{C}_{2} \mathrm{~T}_{x}$ further downshifts to $5.1^{\circ}$, which suggests the introduction of sulfur nanoparticles is effective to alleviate restacking of $\mathrm{Ti}_{3} \mathrm{C}_{2} \mathrm{~T}_{x}$ nanosheets. Compared to S@MGA, the diffraction peaks of S nanoparticles 

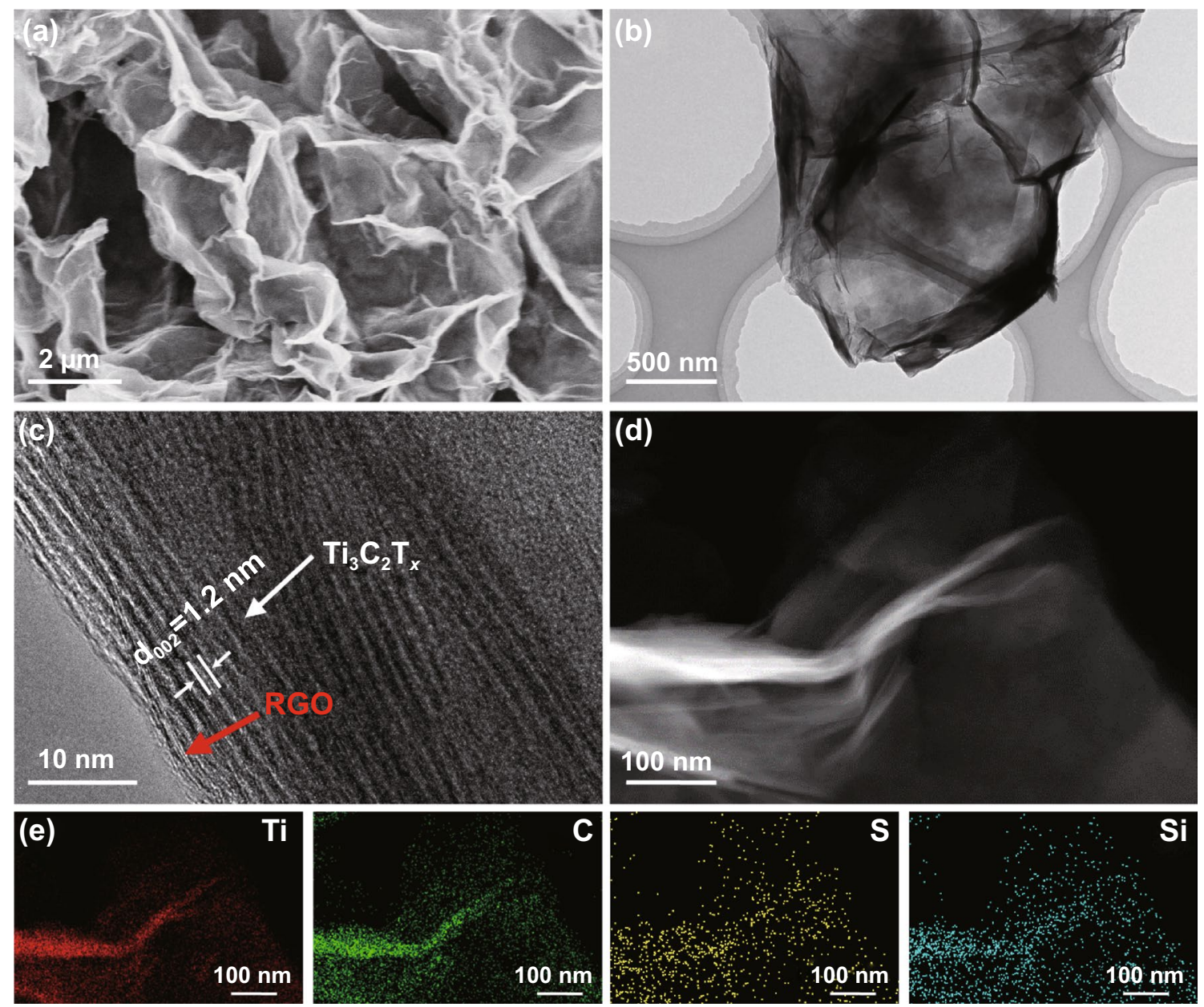

Fig. 3 a SEM image, b-c TEM images, d high-angle annular dark-field image with e the corresponding EDS mapping of SMGA

disappear for SMGA, which is in line with the TEM results. More importantly, the $\mathrm{Ti}_{3} \mathrm{C}_{2} \mathrm{~T}_{x}$ (002) peak for the SMGA shifts to smaller angles than that of MGA, which indicates the enlarged interlayer distance after sulfur modification. There is no obvious characteristic peak of anatase $\mathrm{TiO}_{2}$ for both MGA and SMGA samples, which show that the $\mathrm{Ti}_{3} \mathrm{C}_{2} \mathrm{~T}_{x}$ in the aerogel has not been significantly oxidized. The compositions of the as-prepared specimens have been further investigated by Raman spectroscopy. As shown in Fig. $4 \mathrm{~b}, \mathrm{MGA}$ and SMGA present obvious $\mathrm{D}$ and $\mathrm{G}$ bands of RGO at 1349 and $1589 \mathrm{~cm}^{-1}$, respectively [48]. Besides, the MGA and SMGA monoliths show the typical modes identical to that of $\mathrm{Ti}_{3} \mathrm{C}_{2} \mathrm{~T}_{x}$ film before $800 \mathrm{~cm}^{-1}$. Specifically, the mode at $198 \mathrm{~cm}^{-1}$ is the $\mathrm{A}_{1 \mathrm{~g}}$ symmetry out-of-plane vibrations of Ti atoms, while the modes at 377 and $623 \mathrm{~cm}^{-1}$ are the $\mathrm{E}_{\mathrm{g}}$ group vibrations, including in-plane (shear) modes of
$\mathrm{Ti}, \mathrm{C}$, and surface functional group atoms $[49,50]$. Noteworthily, no Raman mode of the $\mathrm{Ti}_{3} \mathrm{C}_{2} \mathrm{~T}_{x}$ oxidation degradation product of $\mathrm{TiO}_{2}$ is detected, which agrees with the TEM and XRD results, consolidating the stability of $\mathrm{Ti}_{3} \mathrm{C}_{2} \mathrm{~T}_{x}$ during the assembling process. This is pivotal to deliver the attractive physicochemical properties of $\mathrm{Ti}_{3} \mathrm{C}_{2} \mathrm{~T}_{x}$ nanosheets in 3D monolithic form for target applications. The sulfur nanoparticles can reduce the restacking of $\mathrm{Ti}_{3} \mathrm{C}_{2} \mathrm{~T}_{x}$ nanosheets to increase the exposed surface area, which has been further confirmed by the $\mathrm{N}_{2}$ adsorption/desorption measurements (Fig. 4c). Both samples exhibit typical type-IV behavior with a distinct hysteresis loop of type H3. The specific surface area of SMGA $\left(29.2 \mathrm{~m}^{2} \mathrm{~g}^{-1}\right)$ is higher than that of pure $\mathrm{Ti}_{3} \mathrm{C}_{2} \mathrm{~T}_{x}\left(6.7 \mathrm{~m}^{2} \mathrm{~g}^{-1}\right)$ and MGA $\left(14.3 \mathrm{~m}^{2} \mathrm{~g}^{-1}\right)$, indicative of the improved surface accessibility of $\mathrm{Ti}_{3} \mathrm{C}_{2} \mathrm{~T}_{x}$ by the $3 \mathrm{D}$ assembly and sulfur modification. 

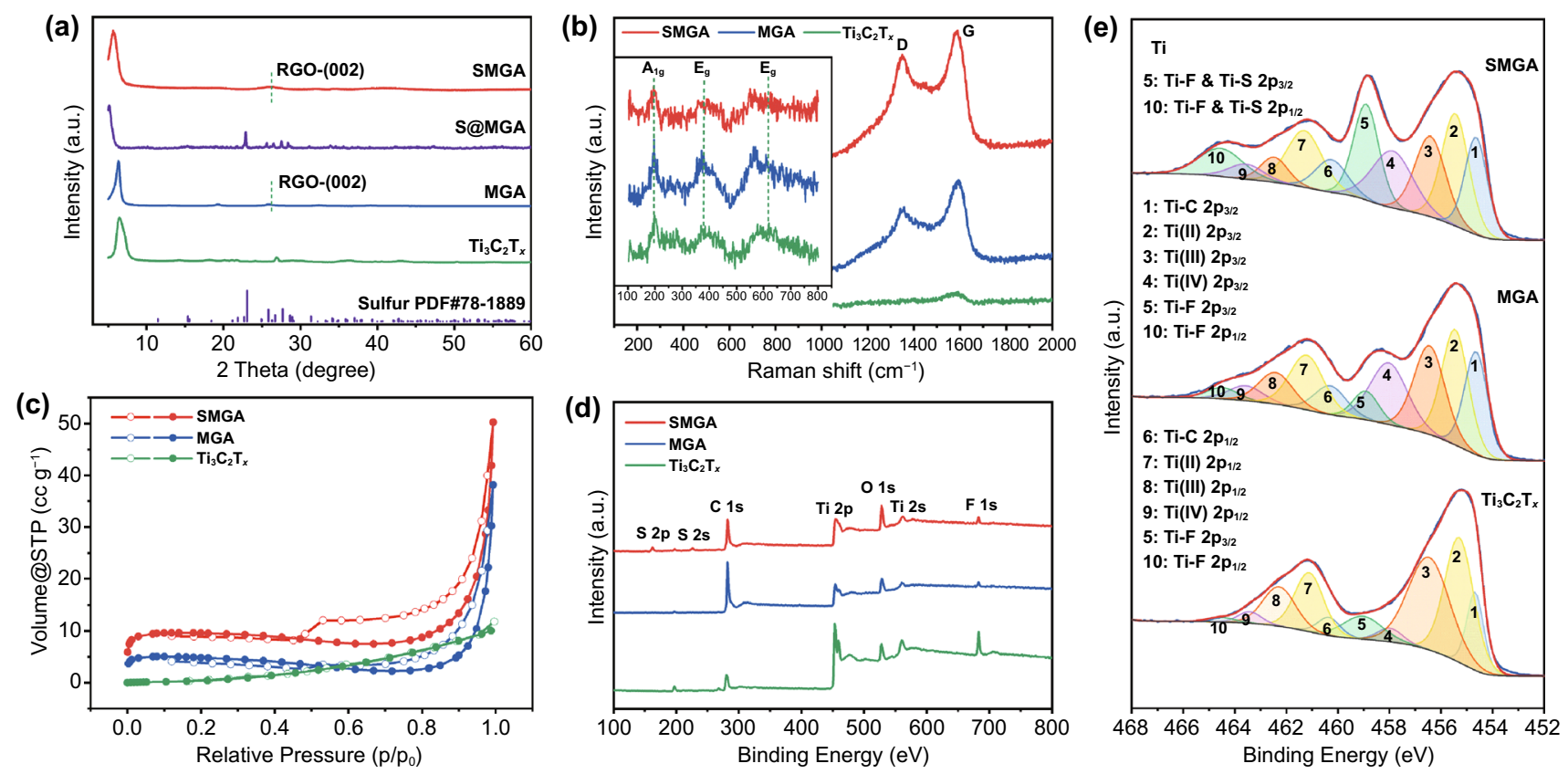

Fig. 4 a XRD patterns of the $\mathrm{Ti}_{3} \mathrm{C}_{2} \mathrm{~T}_{x}$, MGA, MGA@S, and SMGA. b Raman spectra of $\mathrm{Ti}_{3} \mathrm{C}_{2} \mathrm{~T}_{x}$, MGA, and SMGA. c N 2 adsorption-desorption isotherms of $\mathrm{Ti}_{3} \mathrm{C}_{2} \mathrm{~T}_{x}$, MGA and SMGA. d XPS survey spectra of $\mathrm{Ti}_{3} \mathrm{C}_{2} \mathrm{~T}_{x}, \mathrm{MGA}$, and SMGA. e Ti $2 \mathrm{p}$ spectra of $\mathrm{Ti}_{3} \mathrm{C}_{2} \mathrm{~T}_{x}, \mathrm{MGA}$, and SMGA

XPS has been used to investigate the surface chemistry of the assembled aerogels. As shown in Fig. 4d, the predominant signals of $\mathrm{C} 1 \mathrm{~s}$, Ti 2p, Ti $2 \mathrm{~s}, \mathrm{O} 1 \mathrm{~s}$, and F $1 \mathrm{~s}$ are found in the survey XPS spectra of the $\mathrm{Ti}_{3} \mathrm{C}_{2} \mathrm{~T}_{x}$, MGA, and SMGA. Additional peaks at around 164 and $227 \mathrm{eV}$ are observed for SMGA, corresponding to $\mathrm{S} 2 \mathrm{~s}$ and $\mathrm{S} 2 \mathrm{p}$ peaks, respectively. Thermogravimetric analysis (TGA) shows that SMGA has an almost identical mass loss behavior to MGA during heat-treatment to $800{ }^{\circ} \mathrm{C}$ (Fig. S7). Thus, it can be inferred that there is almost no residual elemental sulfur in SMGA, which agrees well with the TEM and XRD results as aforementioned. As shown in the S 2p XPS spectrum (Fig. S8), the existence of Ti-S bond indicates that sulfur bonds with $\mathrm{Ti}_{3} \mathrm{C}_{2} \mathrm{~T}_{x}$. Furthermore, the two peaks at 163.5 and $164.5 \mathrm{eV}$ corresponding to the terminal and the bridging S-S bonds can be identified as a sulfur chain fixed to the surface of $\mathrm{Ti}$ atoms. This suggests that the $\mathrm{S}$ element modifies the surface of $\mathrm{Ti}_{3} \mathrm{C}_{2} \mathrm{~T}_{x}$ by substituting the functional group on its surface [51]. For Ti 2p XPS spectra of bare $\mathrm{Ti}_{3} \mathrm{C}_{2} \mathrm{~T}_{x}$ and MGA, the peaks at 459.0 and $464.5 \mathrm{eV}$ are assigned to Ti $2 \mathrm{p}_{3 / 2}$ and $\mathrm{Ti} 2 \mathrm{p}_{1 / 2}$ of Ti-F, respectively (Fig. 4e). Obviously, the relative intensities of this pair of peaks increase for SMGA, which could be ascribed to the emergence of Ti-S bonds. The combined characterization results show that sulfur modification not only increases the surface accessibility of the monolith but also leads to the sulfur doping of $\mathrm{Ti}_{3} \mathrm{C}_{2} \mathrm{~T}_{x}$. Furthermore, Si XPS peak originating from APTES is observed for MGA and SMGA (Fig. S9), which is in accordance with the EDS mapping results.

To verify the electrochemical advantages of the obtained aerogel and evaluate the effect of the sulfur modification, we have tested the electrochemical properties of SMGA and MGA as the freestanding electrode for sodium-ion storage. Quasi-linear galvanostatic charge-discharge curves without apparent charge/discharge plateaus are observed for MGA (Fig. S10) and SMGA (Fig. 5a). Specifically, the MGA electrode with a mass loading of $1.5 \mathrm{mg} \mathrm{cm}^{-2}$ delivers a discharge capacity of $257 \mathrm{mAh}^{-1}$ with a charge capacity of $112 \mathrm{mAh} \mathrm{g}^{-1}$ in the first cycle at $100 \mathrm{~mA} \mathrm{~g}^{-1}$, where the capacity loss can be ascribed to the formation of solid electrolyte interface (SEI) and the side reaction of the electrolyte [52]. Notably, SMGA with a similar mass loading of $1.7 \mathrm{mg} \mathrm{cm}^{-2}$ delivers a higher reversible capacity of $155 \mathrm{mAh} \mathrm{g}^{-1}$ than MGA in the first cycle at $100 \mathrm{~mA} \mathrm{~g}^{-1}$, demonstrating that the sulfur modification is effective to boost the electrochemical sodium-ion storage performance. 
Specifically, as shown in Fig. S11, the SMGA maintains its capacity advantage and rate performance over MGA in the long-term cycling. And both electrodes show better electrochemical sodium storage performance than pure $\mathrm{Ti}_{3} \mathrm{C}_{2} \mathrm{~T}_{x}$. As shown in Fig. 5b, the capacity gap between SMGA and MGA gradually increases as the mass loading goes up. Compared with other freestanding MXene-based electrodes for sodium-ion storage, SMGA shows excellent areal capacity [53]. Notably, even with a high mass loading of $12.3 \mathrm{mg} \mathrm{cm}^{-2}$, SMGA retains a reversible gravimetric capacity of $102 \mathrm{mAh} \mathrm{g}^{-1}$, corresponding to an areal capacity of $1.26 \mathrm{mAh} \mathrm{cm}^{-2}$. To investigate the effect of sulfur modification on the enhanced electrochemical performances, the electrochemical charge storage kinetics of the SMGA and MGA electrode have been investigated by cyclic voltammetry (CV) at scan rates from 0.1 to $3 \mathrm{mV} \mathrm{s}^{-1}$ (Figs. 5c and S12a). A pair of broad cathodic/anodic peaks located at around 0.5/1.4 V are observed, corresponding to the electrochemical reaction between $\mathrm{Na}^{+}$and $\mathrm{Ti}_{3} \mathrm{C}_{2} \mathrm{~T}_{x}$. Figures $5 \mathrm{~d}$ and $\mathrm{S} 12 \mathrm{~b}$ show the relationships between the anodic/cathodic peak current $(i)$ and the scan rate $(v)$ of the SMGA and MGA, respectively. And the slopes of the linearly fitted plots of $\log (v)-\log (i)$ for the cathodic/anodic peaks are $0.84 / 0.83$ for MGA (Fig. S12b) and 0.89/0.89 for SMGA (Fig. 5d), which suggests that the charge storage process in the is predominantly controlled by a fast capacitive behavior [54]. The contributions of surface-driven capacitive reactions at different scan rates $\left(k_{1} \nu\right)$ can be evaluated
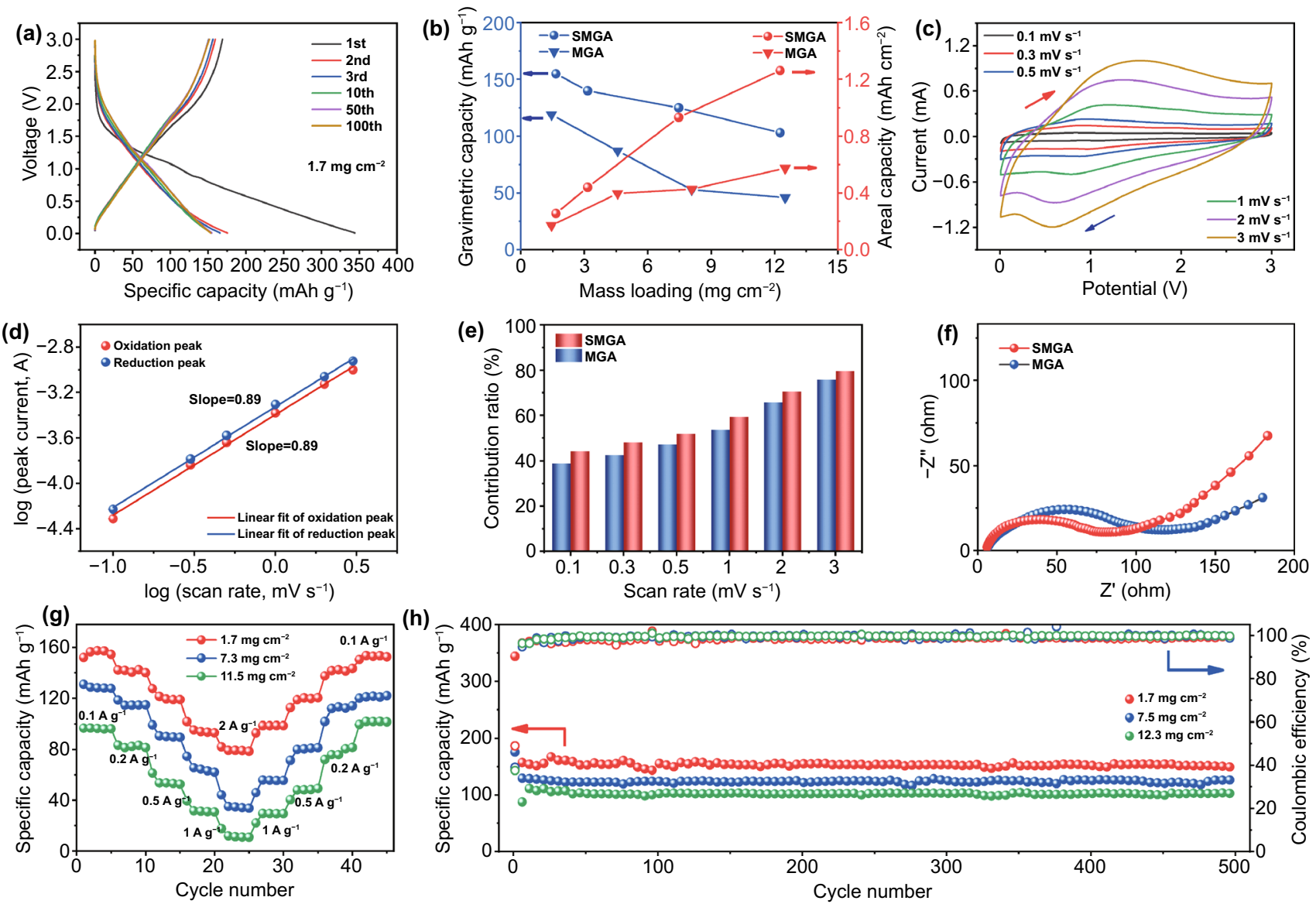

(h)

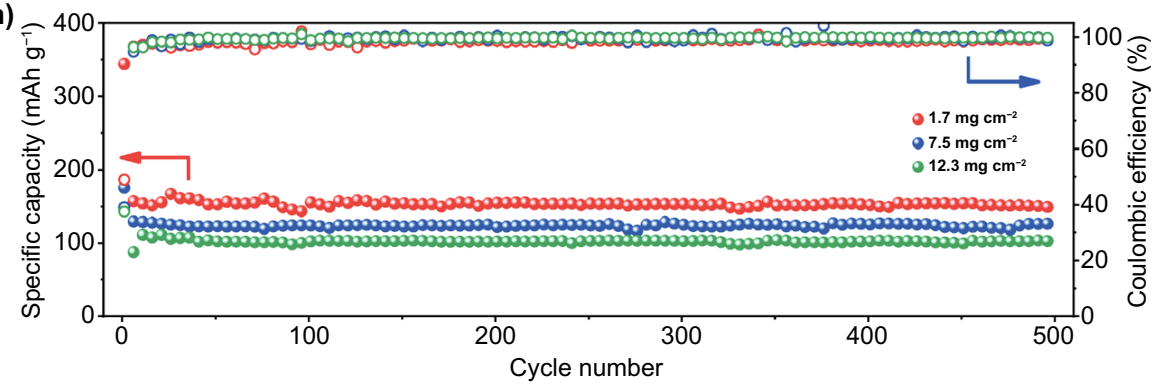

Fig. 5 Half-cell tests of the freestanding SMGA and MGA electrodes for electrochemical sodium-ion storage. a Galvanostatic charge-discharge profiles of SMGA at $100 \mathrm{~mA} \mathrm{~g}^{-1}$. b Gravimetric and areal capacities of SMGA and MGA with different areal densities at $100 \mathrm{~mA} \mathrm{~g}^{-1}$. $\mathbf{c}$ CV curves of the SMGA electrode at different scan rates from 0.1 to $3 \mathrm{mV} \mathrm{s}^{-1}$. d Relationship between the peak current and scan rate for the SMGA electrode. e Capacitance contributions of SMGA and MGA at different scan rates. $\mathbf{f}$ Nyquist plots of SMGA and MGA in Na-ion half-cell. $\mathbf{g}$ Rate performances of the SMGA electrodes with different mass loadings at rates ranging from 0.1 to $5 \mathrm{~A} \mathrm{~g}^{-1}$. $\mathbf{h}$ Cycling performances and Coulombic efficiencies of the SMGA electrodes with different mass loadings at a current density of $0.1 \mathrm{~A} \mathrm{~g}^{-1}$ 
based on the formula of $i=k_{1} v+k_{2} \nu^{1 / 2}$ [7]. As summarized in Fig. 5e, SMGA shows a higher capacitive contribution of $44.4 \%$ than MGA $(38.8 \%)$ at $0.1 \mathrm{mV} \mathrm{s}^{-1}$. The proportions of the capacitive contribution gradually increase at higher scan rates for both MGA and SMGA, and the value for SMGA remains higher than that of MGA. The Nyquist plots for the SMGA and MGA electrodes are compared in Fig. 5f. A steeper sloping line in the low-frequency region for SMGA than that of MGA is observed, which suggests a better electrolyte ion diffusion in the SMGA electrode due to the improved surface accessibility as evidenced by the previous BET surface area results. It is also noted that the charge transfer impedance $\left(R_{\mathrm{ct}}\right)$ of SMGA decreases to $50.9 \Omega$ as compared to the counterpart of MGA (59.8 $\Omega$ ), evidencing the enhanced charge transfer kinetics in SMGA. Linear fit of the Warburg impedance of SMGA and MGA electrodes correlates to different $\mathrm{Na}^{+}$diffusion efficiency. The decreased slope of the $Z^{\prime}-\omega^{-1 / 2}$ curve for the SMGA electrode compared to that of MGA demonstrates improved $\mathrm{Na}^{+}$diffusion efficiency (Fig. S13) [55]. As shown in Fig. S14, it is measured that the electrical conductivity of SMGA is 5190 $\mathrm{S} \mathrm{cm}^{-1}$, which is higher than that of MGA $\left(4210 \mathrm{~S} \mathrm{~cm}^{-1}\right)$. In addition, a previous theoretical investigation shows that the surface sulfur doping of $\mathrm{Ti}_{3} \mathrm{C}_{2} \mathrm{~T}_{x}$ reduced the $\mathrm{Na}^{+}$diffusion barrier [41]. Consequently, these factors cooperatively contribute to boosting the charge transfer kinetics in SMGA. Based on the investigations, the improved electrochemical performances of SMGA compared to MGA for sodium-ion storage can be attributed to the sulfur modification effect on: (i) improving the surface accessibility of SMGA compared to MGA, and (ii) enhancing the charge transfer kinetics by increasing the electrical conductivity and reducing the $\mathrm{Na}^{+}$ diffusion barrier. The rate capability of the SMGA electrode with incremental areal density at different current densities (from 0.1 to $2 \mathrm{~A} \mathrm{~g}^{-1}$ ) is shown in Fig. $5 \mathrm{~g}$. At a high current density of $2 \mathrm{~A} \mathrm{~g} \mathrm{~g}^{-1}$, the SMGA electrode with a mass loading of $1.7 \mathrm{mg} \mathrm{cm}^{-2}$ delivers a capacity of $80 \mathrm{mAh} \mathrm{g}^{-1}$, while a thicker electrode with a mass loading of $11.5 \mathrm{mg} \mathrm{cm}^{-2}$ achieves a capacity of $11 \mathrm{mAh} \mathrm{g}^{-1}$. Figure $5 \mathrm{~h}$ displays the long-cycling profile of the SMGA electrode at the current density of $0.1 \mathrm{~A} \mathrm{~g} \mathrm{~g}^{-1}$. There is almost no capacity decay for all electrodes from the 10th to 500th cycle and discharge capacities of 155,122 , and $102 \mathrm{mAh} \mathrm{g}^{-1}$ are obtained after 500 cycles for the SMGA electrode with a mass loading of $1.7,7.5$, and $12.3 \mathrm{mg} \mathrm{cm}^{-2}$, respectively.
To further confirm the practical feasibility of the 3D porous composite aerogel for electrochemical energy storage, hybrid sodium-ion capacitors (SIC) are assembled by employing SMGA as the anode and commercial activated carbon (AC) as the cathode (Fig. 6a). As shown in Fig. 6b (top part), the $\mathrm{AC}$ cathode has been tested in the potential window of $2-4 \mathrm{~V}\left(\mathrm{vs} \mathrm{Na}^{+} / \mathrm{Na}\right)$, which shows a CV curve of a typical rectangular shape corresponding to a reversible adsorption-desorption charge storage mechanism of anionic $\mathrm{ClO}_{4}{ }^{-}$on the surface of AC. And the spindle-shaped anode profile tested at $0.01-3 \mathrm{~V}$ represents the electrochemical process of $\mathrm{Na}^{+}$in the SMGA electrode. The charge balance between the cathode and anode is controlled based on the equation of $\mathrm{m}_{+} \mathrm{C}_{+}=\mathrm{m}_{-} \mathrm{C}_{-}$, where $\mathrm{m}_{+}$and $\mathrm{m}_{-}$are the mass of the activated material, $\mathrm{C}_{+}$and $\mathrm{C}_{-}$are the specific capacity of anode and cathode, respectively [56]. Consequently, the active material mass ratio of the cathode/anode $\left(\mathrm{m}_{+} / \mathrm{m}_{-}\right)$is determined to be about $4: 1$ based on the specific capacities of AC and SMGA (Fig. S14). CV curves of the assembled AC//SMGA SIC at scan rates of $10-100 \mathrm{mV} \mathrm{s}^{-1}$ are shown in Fig. 6b (bottom part). The slightly distorted quasi-rectangular CV curves imply the mixed Faradaic and non-Faradaic charge-storage process. The rate capability of the AC//SMGA SIC at different current densities (from 0.5 to $5 \mathrm{~A} \mathrm{~g}^{-1}$ ) is shown in Fig. 6c. At a high current density of $5 \mathrm{~A} \mathrm{~g} \mathrm{~g}^{-1}$, the SMGA electrode still delivers a capacity of $70 \mathrm{mAh} \mathrm{g}^{-1}$, which is a vital performance indicator for SIC devices requiring fast charge and discharge. The energy and power densities of the SIC have been calculated based on the total weight of AC and SMGA. As shown in Fig. 6d, compared with the SICs reported previously [57-59], the SIC assembled with SMGA shows competing energy densities with outstanding power densities. Typical device energy densities of 41 and $25 \mathrm{Wh} \mathrm{kg}^{-1}$ have been achieved at the power densities of 197 and $2473 \mathrm{~W} \mathrm{~kg}^{-1}$, respectively. Stable cycling performance is also demonstrated for the AC// SMGA SIC (Fig. 6e). Specifically, the AC//SMGA SIC displays a reversible capacity of $93.7 \mathrm{mAh} \mathrm{g}^{-1}$ (calculated based on the mass of the anode) after 1600 cycles with a high Coulombic efficiency of above $99.5 \%$ at a current density of $0.5 \mathrm{~A} \mathrm{~g}^{-1}$, corresponding to a capacity retention of 92.9\%. And the assembled SIC shows a specific capacity of $60.5 \mathrm{mAh} \mathrm{g}^{-1}$ after 6000 cycles at a current density of 2 $\mathrm{A} \mathrm{g}^{-1}$, which corresponds to a $67 \%$ capacity retention. For a more intuitive demonstration, the AC//SMGA SICs have been used to power various electronic devices (Fig. 6f). A 


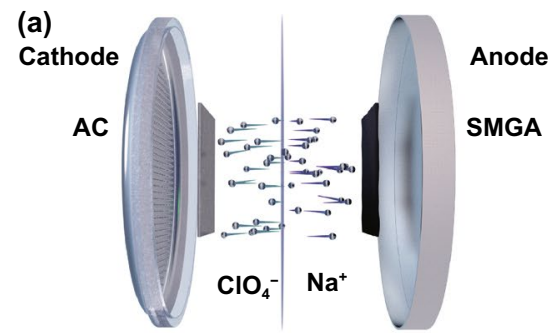

Hybrid sodium-ion capacitor

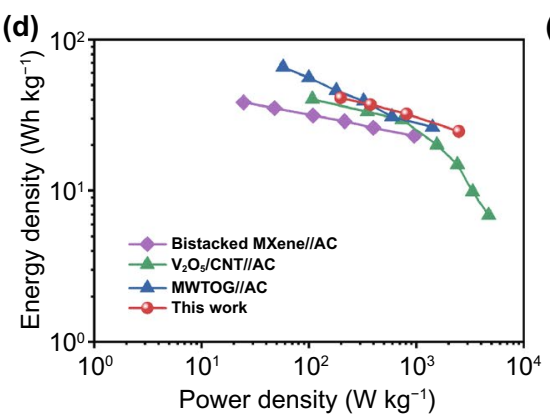

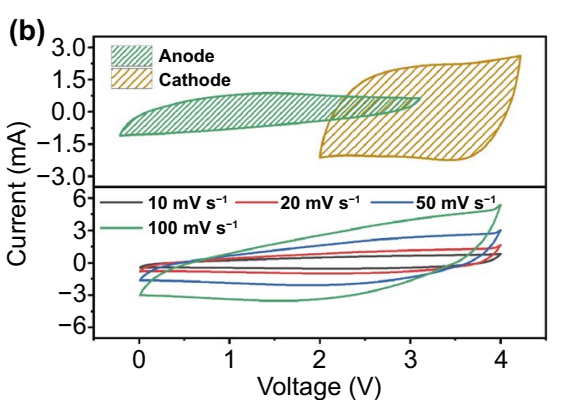

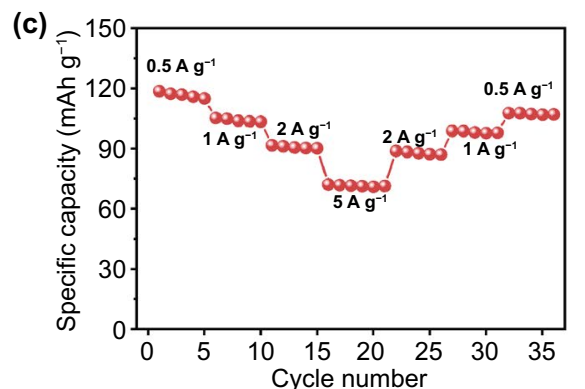

(e)

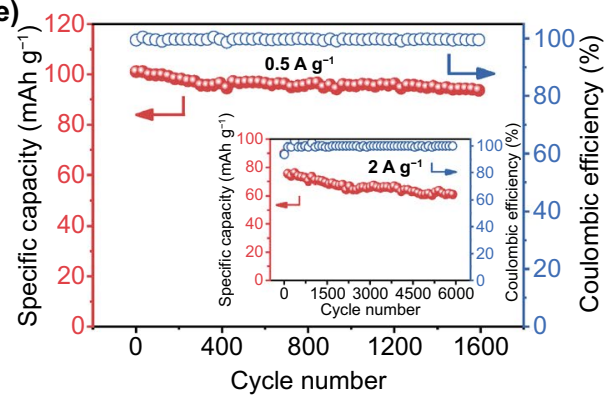

(f)

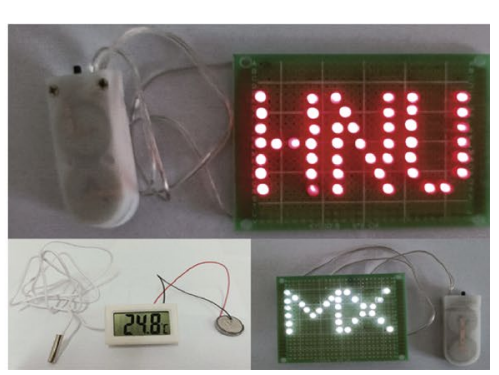

Fig. 6 a Schematics of the assembled AC//SMGA hybrid sodium-ion capacitor (SIC). b CV curves of SMGA and AC in a Na-ion half-cell at a scan rate of $10 \mathrm{mV} \mathrm{s}^{-1}$ (top part) and AC//SMGA SIC at different scan rates (bottom part). $\mathbf{c}$ Rate performances of the AC//SMGA SIC at rates ranging from 0.5 to $5 \mathrm{~A} \mathrm{~g}^{-1}$. d Ragone plots of the AC//SMGA SIC compared to previously reported SICs: Bistacked MXene//AC [57], $\mathrm{V}_{2} \mathrm{O}_{5} /$ $\mathrm{CNT//AC} \mathrm{[58],} \mathrm{and} \mathrm{TiO}_{2}$ mesocage-graphene nanocomposite (MWTOG)//AC [59]. e Long-term cycling performances and Coulombic efficiencies of the AC//SMGA SIC at current densities of $0.5 \mathrm{~A} \mathrm{~g}^{-1}$ and $2 \mathrm{~A} \mathrm{~g}^{-1}$ (inset). $\mathrm{f}$ Digital photos of LED arrays and electronic thermometer powered by the assembled AC//SMGA SIC

few English letters composed of 47 light-emitting diodes (LEDs) can be illuminated by two AC//SMGA SICs, and a digital thermometer is successfully powered by one SIC.

\section{Conclusions}

In summary, $\mathrm{Ti}_{3} \mathrm{C}_{2} \mathrm{~T}_{x} / \mathrm{RGO}$ aerogel has been successfully prepared by GO-assisted assembly of $\mathrm{Ti}_{3} \mathrm{C}_{2} \mathrm{~T}_{x}$ MXene at room temperature in the presence of interfacial mediators, including APTES, $\mathrm{Mn}^{2+}, \mathrm{Fe}^{2+}, \mathrm{Zn}^{2+}$, and $\mathrm{Co}^{2+}$. The interfacial mediators screen the electrostatic repulsion between $\mathrm{Ti}_{3} \mathrm{C}_{2} \mathrm{~T}_{x}$ and $\mathrm{GO}$ effectively to overcome the dispersing effect of $\mathrm{Ti}_{3} \mathrm{C}_{2} \mathrm{~T}_{x}$ for the construction of $\mathrm{Ti}_{3} \mathrm{C}_{2} \mathrm{~T}_{x} /$ RGO monolithic aerogels with a high $\mathrm{Ti}_{3} \mathrm{C}_{2} \mathrm{~T}_{x}$ content of $87 \mathrm{wt} \%$. The assembled $\mathrm{Ti}_{3} \mathrm{C}_{2} \mathrm{~T}_{x} / \mathrm{RGO}$ monolithic aerogel presents excellent structure stability and porous morphology without significant oxidation degradation of $\mathrm{Ti}_{3} \mathrm{C}_{2} \mathrm{~T}_{x}$. On this basis, a further sulfur modification process has been introduced, which is effective to enhance the surface accessibility and charge storage kinetics for electrochemical sodium-ion storage. When fabricated as freestanding electrodes, the electrode with a practical-level mass loading of $12.3 \mathrm{mg} \mathrm{cm}^{-2}$ still delivers an areal capacity of $1.26 \mathrm{mAh} \mathrm{cm}^{-2}$ at a current density of $0.1 \mathrm{~A} \mathrm{~g}^{-1}$. And the promising performances in SIC have been demonstrated by pairing with activated carbon cathode. This work proves the feasibility of the GOassisted gelation process of MXene at room temperature to produce monoliths with a high MXene content and suppressed MXene oxidation degradation, providing more possibilities for the applications of 3D MXene-based aerogels.

Acknowledgements This work was supported by the National Natural Science Foundation of China (52071137, 51977071, 51802040, and 21802020), the Science and Technology Innovation Program of Hunan Province (2021RC3066 and 2021RC3067), and the Natural Science Foundation of Hunan Province (2020JJ3004 and 2020JJ4192). N. Zhang and X. Xie also acknowledge the financial support of the Fundamental Research Funds for the Central Universities.

Funding Open access funding provided by Shanghai Jiao Tong University.

Open Access This article is licensed under a Creative Commons Attribution 4.0 International License, which permits use, sharing, adaptation, distribution and reproduction in any medium or format, 
as long as you give appropriate credit to the original author(s) and the source, provide a link to the Creative Commons licence, and indicate if changes were made. The images or other third party material in this article are included in the article's Creative Commons licence, unless indicated otherwise in a credit line to the material. If material is not included in the article's Creative Commons licence and your intended use is not permitted by statutory regulation or exceeds the permitted use, you will need to obtain permission directly from the copyright holder. To view a copy of this licence, visit http://creativecommons.org/licenses/by/4.0/.

Supplementary Information The online version contains supplementary material available at https://doi.org/10.1007/ s40820-021-00781-6.

\section{References}

1. M. Naguib, M. Kurtoglu, V. Presser, J. Lu, J. Niu et al., Twodimensional nanocrystals produced by exfoliation of $\mathrm{Ti}_{3} \mathrm{AlC}_{2}$. Adv. Mater. 23(37), 4248-4253 (2011). https://doi.org/10. 1002/adma.201102306

2. M. Naguib, O. Mashtalir, J. Carle, V. Presser, J. Lu et al., Two-dimensional transition metal carbides. ACS Nano 6(2), 1322-1331 (2012). https://doi.org/10.1021/nn204153h

3. M. Naguib, V.N. Mochalin, M.W. Barsoum, Y. Gogotsi, 25th anniversary article: MXenes: a new family of two-dimensional materials. Adv. Mater. 26(7), 992-1005 (2014). https://doi.org/ 10.1002/adma.201304138

4. Y. Chen, X. Xie, X. Xin, Z.-R. Tang, Y.-J. Xu, Ti ${ }_{3} \mathrm{C}_{2} \mathrm{~T}_{x}$-based three-dimensional hydrogel by a graphene oxide-assisted selfconvergence process for enhanced photoredox catalysis. ACS Nano 13(1), 295-304 (2019). https://doi.org/10.1021/acsnano. $8 \mathrm{~b} 06136$

5. Y. Ma, Y. Yue, H. Zhang, F. Cheng, W. Zhao et al., 3D synergistical MXene/reduced graphene oxide aerogel for a piezoresistive sensor. ACS Nano 12(4), 3209-3216 (2018). https:// doi.org/10.1021/acsnano.7b06909

6. Z. Lin, J. Liu, W. Peng, Y. Zhu, Y. Zhao et al., Highly stable $3 \mathrm{D} \mathrm{Ti}_{3} \mathrm{C}_{2} \mathrm{~T}_{x}$ MXene-based foam architectures toward highperformance terahertz radiation shielding. ACS Nano 14(2), 2109-2117 (2020). https://doi.org/10.1021/acsnano.9b08832

7. J. Cao, Z. Sun, J. Li, Y. Zhu, Z. Yuan et al., Microbe-assisted assembly of $\mathrm{Ti}_{3} \mathrm{C}_{2} \mathrm{~T}_{x}$ MXene on fungi-derived nanoribbon heterostructures for ultrastable sodium and potassium ion storage. ACS Nano 15(2), 3423-3433 (2021). https://doi.org/10.1021/ acsnano.0c10491

8. J. Luo, J. Zheng, J. Nai, C. Jin, H. Yuan et al., Atomic sulfur covalently engineered interlayers of $\mathrm{Ti}_{3} \mathrm{C}_{2}$ MXene for ultrafast sodium-ion storage by enhanced pseudocapacitance. Adv. Funct. Mater. 29(10), 1808107 (2019). https://doi.org/10.1002/ adfm. 201808107

9. X. Guo, W. Zhang, J. Zhang, D. Zhou, X. Tang et al., Boosting sodium storage in two-dimensional phosphorene/ $\mathrm{Ti}_{3} \mathrm{C}_{2} \mathrm{~T}_{x}$ MXene nanoarchitectures with stable fluorinated interphase.
ACS Nano 14(3), 3651-3659 (2020). https://doi.org/10.1021/ acsnano.0c00177

10. J. Nan, X. Guo, J. Xiao, X. Li, W. Chen et al., Nanoengineering of 2D MXene-based materials for energy storage applications. Small 17(9), 1902085 (2021). https://doi.org/10.1002/ smll.201902085

11. B. Anasori, M.R. Lukatskaya, Y. Gogotsi, 2D metal carbides and nitrides (MXenes) for energy storage. Nat. Rev. Mater. 2(2), 16098 (2017). https://doi.org/10.1038/natrevmats.2016. 98

12. Q. Zhao, Q. Zhu, J. Miao, P. Zhang, P. Wan et al., Flexible 3D Porous MXene foam for high-performance lithium-ion batteries. Small 15(51), 1904293 (2019). https://doi.org/10.1002/ smll.201904293

13. M. Okubo, A. Sugahara, S. Kajiyama, A. Yamada, MXene as a charge storage host. Acc Chem. Res. 51(3), 591-599 (2018). https://doi.org/10.1021/acs.accounts.7b00481

14. B. Cao, H. Liu, P. Zhang, N. Sun, B. Zheng et al., Flexible MXene framework as a fast electron/potassium-ion dual-function conductor boosting stable potassium storage in graphite electrodes. Adv. Funct. Mater. 31(32), 2102126 (2021). https:// doi.org/10.1002/adfm.202102126

15. N. Sun, Q. Zhu, B. Anasori, P. Zhang, H. Liu et al., MXenebonded flexible hard carbon film as anode for stable $\mathrm{Na} / \mathrm{K}$-ion storage. Adv. Funct. Mater. 29(51), 1906282 (2019). https:// doi.org/10.1002/adfm.201906282

16. P. Zhang, R.A. Soomro, Z. Guan, N. Sun, B. Xu, 3D carboncoated MXene architectures with high and ultrafast lithium/ sodium-ion storage. Energy Storage Mater (2020). https://doi. org/10.1016/j.ensm.2020.04.016

17. J. Cao, J. Li, D. Li, Z. Yuan, Y. Zhang et al., Strongly Coupled 2D transition metal chalcogenide-MXene-carbonaceous nanoribbon heterostructures with ultrafast ion transport for boosting sodium/potassium ions storage. Nano-Micro Lett. 13(1), 113 (2021). https://doi.org/10.1007/s40820-021-00623-5

18. J. Xiao, X. Li, K. Tang, D. Wang, M. Long et al., Recent progress of emerging cathode materials for sodium ion batteries. Mater. Chem. Front. 5(10), 3735-3764 (2021). https://doi.org/ 10.1039/D1QM00179E

19. J. Xiao, X. Li, K. Tang, M. Long, J. Chen et al., Enhanced electrochemical performance of Li-rich cathode material for lithium-ion batteries. Surf. Innov. (2021). https://doi.org/10. 1680/jsuin.21.00010

20. G. Li, B.C. Wyatt, F. Song, C. Yu, Z. Wu et al., 2D titanium carbide (MXene) based films: expanding the frontier of functional film materials. Adv. Funct. Mater. 31(46), 2105043 (2021). https://doi.org/10.1002/adfm.202105043

21. P. Lian, Y. Dong, Z.-S. Wu, S. Zheng, X. Wang et al., Alkalized $\mathrm{Ti}_{3} \mathrm{C}_{2}$ MXene nanoribbons with expanded interlayer spacing for high-capacity sodium and potassium ion batteries. Nano Energy 40, 1-8 (2017). https://doi.org/10.1016/j.nanoen. 2017.08.002

22. Y. Ding, Y. Chen, N. Xu, X. Lian, L. Li et al., Facile synthesis of $\mathrm{FePS}_{3}$ nanosheets@ MXene composite as a high-performance anode material for sodium storage. Nano-Micro Lett. 12(1), 54 (2020). https://doi.org/10.1007/s40820-020-0381-y 
23. J. Kong, H. Yang, X. Guo, S. Yang, Z. Huang et al., Highmass-loading porous $\mathrm{Ti}_{3} \mathrm{C}_{2} \mathrm{~T}_{x}$ films for ultrahigh-rate pseudocapacitors. ACS Energy Lett. 5(7), 2266-2274 (2020). https:// doi.org/10.1021/acsenergylett.0c00704

24. S. Zhao, H.-B. Zhang, J.-Q. Luo, Q.-W. Wang, B. Xu et al., Highly electrically conductive three-dimensional $\mathrm{Ti}_{3} \mathrm{C}_{2} \mathrm{~T}_{x}$ MXene/reduced graphene oxide hybrid aerogels with excellent electromagnetic interference shielding performances. ACS Nano 12(11), 11193-11202 (2018). https://doi.org/10. 1021/acsnano.8b05739

25. J. Liu, H.-B. Zhang, R. Sun, Y. Liu, Z. Liu et al., Hydrophobic, flexible, and lightweight MXene foams for high-performance electromagnetic-interference shielding. Adv. Mater. 29(38), 1702367 (2017). https://doi.org/10.1002/adma.201702367

26. K. Li, M. Liang, H. Wang, X. Wang, Y. Huang et al., 3D MXene architectures for efficient energy storage and conversion. Adv. Funct. Mater. 30(47), 2000842 (2020). https://doi. org/10.1002/adfm.202000842

27. Z. Wu, T. Shang, Y. Deng, Y. Tao, Q.-H. Yang, The assembly of MXenes from 2D to 3D. Adv. Sci. 7(7), 1903077 (2020). https://doi.org/10.1002/advs.201903077

28. F. Song, G. Li, Y. Zhu, Z. Wu, X. Xie et al., Rising from the horizon: three-dimensional functional architectures assembled with MXene nanosheets. J. Mater. Chem. A 8(36), 1853818559 (2020). https://doi.org/10.1039/D0TA06222G

29. Y. Deng, T. Shang, Z. Wu, Y. Tao, C. Luo et al., Fast gelation of $\mathrm{Ti}_{3} \mathrm{C}_{2} \mathrm{~T}_{x}$ MXene initiated by metal ions. Adv. Mater. 31(43), 1902432 (2019). https://doi.org/10.1002/adma.201902432

30. S. Zhang, X.-Y. Li, W. Yang, H. Tian, Z. Han et al., Novel synthesis of red phosphorus nanodot/ $\mathrm{T}_{3} \mathrm{C}_{2} \mathrm{~T}_{\mathrm{x}}$ MXenes from low-cost $\mathrm{Ti}_{3} \mathrm{SiC}_{2}$ MAX phases for superior lithium- and sodium-ion batteries. ACS Appl. Mater. Interfaces 11(45), 42086-42093 (2019). https://doi.org/10.1021/acsami.9b13308

31. T. Shang, Z. Lin, C. Qi, X. Liu, P. Li et al., 3D macroscopic architectures from self-assembled MXene hydrogels. Adv. Funct. Mater. 29(33), 1903960 (2019). https://doi.org/10. 1002/adfm.201903960

32. X. Zhang, R. Lv, A. Wang, W. Guo, X. Liu et al., MXene aerogel scaffolds for high-rate lithium metal anodes. Angew. Chem. Int. Ed. 57(46), 15028-15033 (2018). https://doi.org/ 10.1002/anie. 201808714

33. J. Song, X. Guo, J. Zhang, Y. Chen, C. Zhang et al., Rational design of free-standing 3D porous MXene/rGO hybrid aerogels as polysulfide reservoirs for high-energy lithium-sulfur batteries. J. Mater. Chem. A 7(11), 6507-6513 (2019). https://doi.org/10.1039/C9TA00212J

34. C.J. Zhang, S. Pinilla, N. McEvoy, C.P. Cullen, B. Anasori et al., Oxidation stability of colloidal two-dimensional titanium carbides (MXenes). Chem. Mater. 29(11), 4848-4856 (2017). https://doi.org/10.1021/acs.chemmater.7b00745

35. X. Yang, Q. Wang, K. Zhu, K. Ye, G. Wang et al., 3D porous oxidation-resistant MXene/graphene architectures induced by in situ zinc template toward high-performance supercapacitors. Adv. Funct. Mater. 31(20), 2101087 (2021). https:// doi.org/10.1002/adfm.202101087
36. C. Zhang, Interfacial assembly of two-dimensional MXenes. J. Energ. Chem. 60, 417-434 (2021). https://doi.org/10. 1016/j.jechem.2020.12.036

37. S. Abdolhosseinzadeh, J. Heier, C. Zhang, Printing and coating MXenes for electrochemical energy storage devices. J. High Energy Phys. 2(3), 031004 (2020). https://doi.org/10. 1088/2515-7655/aba47d

38. S. Abdolhosseinzadeh, X. Jiang, H. Zhang, J. Qiu, C. Zhang, Perspectives on solution processing of two-dimensional MXenes. Mater. Today (2021). https://doi.org/10.1016/j. mattod.2021.02.010

39. N. Li, J. Peng, W.-J. Ong, T. Ma, Arramel et al., MXenes: an emerging platform for wearable electronics and looking beyond. Matter 4(2), 377-407 (2021). https://doi.org/10. 1016/j.matt.2020.10.024

40. J. Zhu, A. Chroneos, J. Eppinger, U. Schwingenschlögl, S-functionalized MXenes as electrode materials for Li-ion batteries. Appl. Mater. Today 5, 19-24 (2016). https://doi. org/10.1016/j.apmt.2016.07.005

41. Q. Meng, J. Ma, Y. Zhang, Z. Li, C. Zhi et al., The S-functionalized $\mathrm{Ti}_{3} \mathrm{C}_{2}$ Mxene as a high capacity electrode material for Na-ion batteries: a DFT study. Nanoscale 10(7), 33853392 (2018). https://doi.org/10.1039/C7NR07649E

42. G. Li, S. Lian, F. Song, S. Chen, Z. Wu et al., Surface chemistry and mesopore dual regulation by sulfur-promised high volumetric capacity of $\mathrm{Ti}_{3} \mathrm{C}_{2} \mathrm{~T}_{x}$ films for sodium-ion storage. Small (2021). https://doi.org/10.1002/smll.202103626

43. Y. Wei, P. Zhang, R.A. Soomro, Q. Zhu, B. Xu, Advances in the synthesis of 2D MXenes. Adv. Mater. 33(39), 2103148 (2021). https://doi.org/10.1002/adma.202103148

44. M. Alhabeb, K. Maleski, B. Anasori, P. Lelyukh, L. Clark et al., Guidelines for synthesis and processing of two-dimensional titanium carbide $\left(\mathrm{T}_{3} \mathrm{C}_{2} \mathrm{~T}_{\mathrm{x}}\right.$ MXene). Chem. Mater. 29(18), 7633-7644 (2017). https://doi.org/10.1021/acs. chemmater.7b02847

45. W.S. Hummers, R.E. Offeman, Preparation of graphitic oxide. J. Am. Chem. Soc. 80(6), 1339-1339 (1958). https://doi.org/ 10.1021/ja01539a017

46. H. Tang, W. Li, L. Pan, C.P. Cullen, Y. Liu et al., In situ formed protective barrier enabled by sulfur@titanium carbide (MXene) ink for achieving high-capacity, long lifetime Li-S batteries. Adv. Sci. 5(9), 1800502 (2018). https://doi.org/10. 1002/advs.201800502

47. P. Zhang, Q. Zhu, R.A. Soomro, S. He, N. Sun et al., In situ ice template approach to fabricate 3D flexible MXene film-based electrode for high performance supercapacitors. Adv. Funct. Mater. 30(47), 2000922 (2020). https://doi.org/10.1002/adfm. 202000922

48. J. Gao, F. Liu, Y. Liu, N. Ma, Z. Wang et al., Environmentfriendly method to produce graphene that employs vitamin C and amino acid. Chem. Mater. 22(7), 2213-2218 (2010). https://doi.org/10.1021/cm902635j

49. M. Hu, Z. Li, T. Hu, S. Zhu, C. Zhang et al., High-capacitance mechanism for $\mathrm{Ti}_{3} \mathrm{C}_{2} \mathrm{~T}_{x}$ MXene by in situ electrochemical raman spectroscopy investigation. ACS Nano 10(12), 1134411350 (2016). https://doi.org/10.1021/acsnano.6b06597 
50. J. Yan, C.E. Ren, K. Maleski, C.B. Hatter, B. Anasori et al., Flexible MXene/graphene films for ultrafast supercapacitors with outstanding volumetric capacitance. Adv. Funct. Mater. 27(30), 1701264 (2017). https://doi.org/10.1002/adfm.20170 1264

51. W. Bao, C.E. Shuck, W. Zhang, X. Guo, Y. Gogotsi et al., Boosting performance of Na-S batteries using sulfur-doped $\mathrm{Ti}_{3} \mathrm{C}_{2} \mathrm{~T}_{x}$ MXene nanosheets with a strong affinity to sodium polysulfides. ACS Nano 13(10), 11500-11509 (2019). https:// doi.org/10.1021/acsnano.9b04977

52. J. Li, D. Yan, S. Hou, Y. Li, T. Lu et al., Improved sodium-ion storage performance of $\mathrm{Ti}_{3} \mathrm{C}_{2} \mathrm{~T}_{x}$ MXenes by sulfur doping. $\mathrm{J}$. Mater. Chem. A 6(3), 1234-1243 (2018). https://doi.org/10. 1039/C7TA08261D

53. M.-Q. Zhao, X. Xie, C.E. Ren, T. Makaryan, B. Anasori et al., Hollow MXene spheres and 3D macroporous MXeneframeworks for Na-ion storage. Adv. Mater. 29(37), 1702410 (2017). https://doi.org/10.1002/adma.201702410

54. J. Wang, J. Polleux, J. Lim, B. Dunn, Pseudocapacitive contributions to electrochemical energy storage in $\mathrm{TiO}_{2}$ (anatase) nanoparticles. J. Phys. Chem. C 111(40), 14925-14931 (2007). https://doi.org/10.1021/jp074464w
55. X. Yang, A.L. Rogach, Electrochemical techniques in battery research: a tutorial for nonelectrochemists. Adv. Energy Mater. 9(25), 1900747 (2019). https://doi.org/10.1002/aenm.20190 0747

56. Y. Peng, R. Zhang, B. Fan, W. Li, Z. Chen et al., Optimized kinetics match and charge balance toward potassium ion hybrid capacitors with ultrahigh energy and power densities. Small 16(42), 2003724 (2020). https://doi.org/10.1002/smll. 202003724

57. N. Kurra, M. Alhabeb, K. Maleski, C.-H. Wang, H.N. Alshareef et al., Bistacked titanium carbide (MXene) anodes for hybrid sodium-ion capacitors. ACS Energy Lett. 3(9), 20942100 (2018). https://doi.org/10.1021/acsenergylett.8b01062

58. Z. Chen, V. Augustyn, X. Jia, Q. Xiao, B. Dunn et al., Highperformance sodium-ion pseudocapacitors based on hierarchically porous nanowire composites. ACS Nano 6(5), 43194327 (2012). https://doi.org/10.1021/nn300920e

59. Z. Le, F. Liu, P. Nie, X. Li, X. Liu et al., Pseudocapacitive sodium storage in mesoporous single-crystal-like $\mathrm{TiO}_{2}$-graphene nanocomposite enables high-performance sodium-ion capacitors. ACS Nano 11(3), 2952-2960 (2017). https://doi. org/10.1021/acsnano.6b08332 